\title{
Calibration of the Mars Science Laboratory Alpha Particle X-ray Spectrometer
}

\author{
John L. Campbell • Glynis M. Perrett • Ralf Gellert • Stefan M. Andrushenko • \\ Nicholas I. Boyd · John A. Maxwell · Penelope L. King • Céleste D.M. Schofield
}

Received: 14 September 2011 / Accepted: 14 March 2012 / Published online: 5 April 2012

(C) Springer Science+Business Media B.V. 2012

\begin{abstract}
The alpha-particle X-ray spectrometer (APXS) for the Mars Science Laboratory (MSL) mission was calibrated for routine analysis of: $\mathrm{Na}, \mathrm{Mg}, \mathrm{Al}, \mathrm{Si}, \mathrm{P}, \mathrm{S}, \mathrm{Cl}, \mathrm{K}, \mathrm{Ca}, \mathrm{Ti}$, $\mathrm{Cr}, \mathrm{Mn}, \mathrm{Fe}, \mathrm{Ni}, \mathrm{Zn}, \mathrm{Br}, \mathrm{Rb}, \mathrm{Sr}$, and $\mathrm{Y}$. The following elements were also calibrated, but may be too low to be measured (10s-100s ppm) for their usual abundance on Mars: V, Cu, $\mathrm{Ga}$, As, Se and W. An extensive suite of geological reference materials, supplemented by pure chemical elements and compounds was used. Special attention was paid to include phyllosilicates, sulfates and a broad selection of basalts as these are predicted minerals and rocks at the Gale Crater landing site. The calibration approach is from first principles, using fundamental physics parameters and an assumed homogeneous sample matrix to calculate expected elemental signals for a given instrument setup and sample composition. Resulting concentrations for most elements accord with expected values. Deviations in elements of lower atomic number $(\mathrm{Na}, \mathrm{Mg}, \mathrm{Al})$ indicate significant influences of mineral phases, especially in basalts, ultramafic rocks and trachytes. The systematics of these deviations help us to derive empirical, iterative corrections for different rock groups, based on a preliminary APXS analysis which assumes a homogeneous sample. These corrections have the potential to significantly improve the accuracy of APXS analyses, especially when other MSL instrument results, such as the X-ray diffraction data from CheMin, are included in the overall analysis process.
\end{abstract}

Keywords Mars $\cdot$ MSL $\cdot$ APXS $\cdot$ Calibration $\cdot$ Geochemical analysis

J.L. Campbell (凶) · G.M. Perrett · R. Gellert · S.M. Andrushenko · N.I. Boyd · J.A. Maxwell Guelph-Waterloo Physics Institute, University of Guelph, Guelph, Ontario, Canada N1G 2W1 e-mail: icampbel@uoguelph.ca

P.L. King

Institute for Meteoritics, University of New Mexico, Albuquerque, NM 87131, USA

P.L. King · C.D.M. Schofield

Department of Earth Sciences, University of Western Ontario, London, Ontario, Canada N6A 5B7 


\section{Overall Strategy}

The alpha-particle X-ray spectrometer (APXS) which will perform elemental analysis during the Mars Science Laboratory (MSL) mission is described in detail by Gellert et al. (2012) in this volume. As was the case for the MER APXS (Gellert et al. 2006), calibration of such a planetary exploration instrument is a two-part exercise. First, the analytical method, which is a unique combination of X-ray fluorescence (XRF) and particle-induced X-ray emission (PIXE), is calibrated by measuring spectra from a suite of geochemical reference materials (GRM), described in detail below, using the flight-equivalent unit (FEU) APXS instrument. The primary objective is to determine the element concentrations in these GRMs and to compare the results with the values recommended by the suppliers. Secondary objectives are to ascertain if and how these results are influenced by matrix effects caused by the specific mineralogy of each GRM, and to assess the resultant uncertainties which should be attached to analyses during the MSL mission.

In a second step, the small impacts of different instruments and sources are determined by a cross-calibration. In principle, the FEU calibration should hold for all identically designed units, including the flight unit (PFM). However, in practice there can be differences between these two APXS units, mainly stemming from the detectors and the ${ }^{244} \mathrm{Cm}$ sources. The efficiency of the X-ray detectors may differ, especially for the low-energy X-rays of the lightest elements; and the intensity ratio between alpha particles and plutonium X-rays emitted by the ${ }^{244} \mathrm{Cm}$ sources may differ. These factors were determined via a laboratory "cross-calibration" of the two units, employing a subset of the standards.

\section{The MSL APXS Calibration Set}

To calibrate the FEU APXS instrument for MSL, the GRM suite was more than doubled relative to that used for calibration of the MER APXS. We chose a sample suite to ensure that almost all elements observed in the MER mission were well represented over the reported concentration ranges (see e.g. Gellert et al. 2006; Squyres et al. 2008).

To make informed choices as to the best GRMs for calibration, we compiled a database of available GRMs from the literature that included 471 certified and validated samples from 29 sources and included igneous rocks (109), sediments and sedimentary rocks (233) and 'minerals' (129). The 'minerals' group contains samples that are dominated by a particular mineral, but few of these standards are truly mono-mineralic.

From our GRM database, we chose $\sim 30$ additional GRMs over and above the MER calibration set to fill out the abundances of $\mathrm{Al}, \mathrm{Ti}, \mathrm{Mg}, \mathrm{Cr}, \mathrm{Mn}, \mathrm{Ca}, \mathrm{K}, \mathrm{Na}, \mathrm{P}, \mathrm{Cl}, \mathrm{Br}, \mathrm{Zn}$ and Ni relative to the range of elements found on Mars. Details are in Fig. 1 and Table 1. Representation of sediments/sedimentary rocks is increased by a factor of five over MER.

The new suite of GRMs better serves to test the calibration for lower atomic number elements ( $\mathrm{Na}, \mathrm{Mg}$ and $\mathrm{Al}$ ). The MSL GRMs have a strong correlation between $\mathrm{SiO}_{2}$ and the lower $\mathrm{Z}$ elements, typical of the correlations between elements observed in igneous fractionation series. The additional data points will minimize that correlation and allow us to examine the lower $\mathrm{Z}$ elements at approximately constant $\mathrm{SiO}_{2}$ content.

In some cases, concentrations of the very light elements in significant abundance, such as bound water $\left(\mathrm{H}_{2} \mathrm{O}+\right), \mathrm{CO}_{2}, \mathrm{SO}_{3}, \mathrm{~N}$-species and various important trace elements such as $\mathrm{Cl}$ and $\mathrm{Br}$, were missing or provisional (i.e. having unknown accuracy) in the suppliers' certificates. For these reasons, the majority of the GRMs underwent a commercial, state-ofthe-art blind analysis at Activation Laboratories Inc., Ancaster, Ontario. 


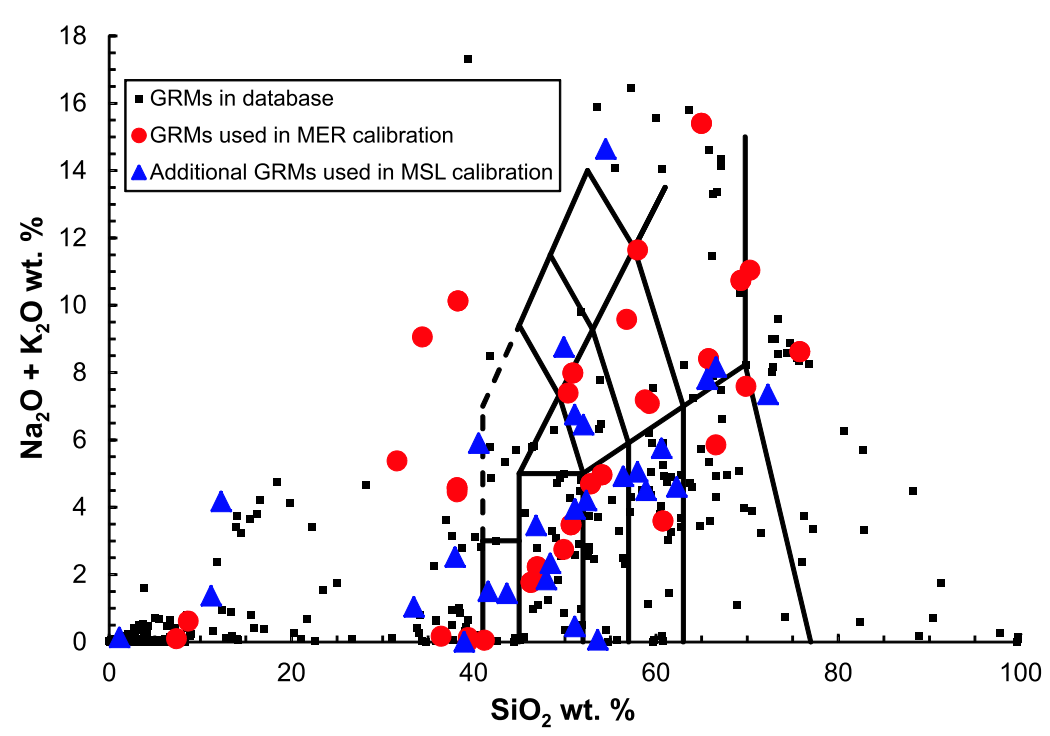

Fig. 1 Total alkalis versus $\mathrm{SiO}_{2}$ diagram with fields for igneous rocks from Le Maitre (2002) showing available GRM standards from our database (small squares), MER calibration standards (circles), and our additional GRM standards (triangles)

Most of the MSL calibration samples have siliceous matrices because siliceous matrices are expected as the most common type of sample on Mars. This places a limitation on the variety of matrix effects that may be encountered. However, other pure minerals and chemical compounds (e.g. phosphates, sulfates, chlorides) were also measured to cover a large range of different matrices. Some of these are employed here, in cases where the siliceous GRMs prove insufficient to the task.

\section{Sample Preparation}

For the FEU calibration, powdered GRMs were passed through a 250 micron mesh sieve to break up any clumped material. The sieved samples were heated in a $110{ }^{\circ} \mathrm{C}$ oven for at least 2 hours, and then stored in a desiccator. Prior to analysis, the sample was poured into a round $\mathrm{Al}$ sample cup with an inner diameter of $40 \mathrm{~mm}$ and a depth of $13 \mathrm{~mm}$, and the surface was flattened with a plunger to render it as smooth as possible at a reproducible distance below the lip. In all cases, the thickness of the sample was $>2 \mathrm{~mm}$. One or more spacer discs were included at the bottom of the cup to economize on sample material; the spacer material chosen was rich in $\mathrm{Br}$, so that a sample which was too thin would be detected by the presence of Br X-rays in the spectrum. All GRM samples were analyzed in the APXS calibration chamber with the FEU instrument as described by Gellert et al. (2012).

\section{Treatment of X-ray Spectra for APXS FEU Calibration}

Our approach to deriving chemistry from APXS spectra follows largely from our recent recalibration of the equivalent MER instrument (Campbell et al. 2011a, 2011b), and so only a brief overview of essentials is given here. It employs a spectrum fitting code, GUAPX, which 
Table 1 Distribution of certified geochemical reference materials among sample groups in the APXS calibration exercise

\begin{tabular}{|c|c|}
\hline Sample group & GRM suppliers ${ }^{\mathrm{a}}$ and identification \\
\hline \multicolumn{2}{|l|}{ Igneous rocks } \\
\hline Minerals & $\begin{array}{l}\text { SARM: AL-I, DT-N, FK-N, GL-O, Mica-Fe, Mica-Mg, ZW-C, UB-N; } \\
\text { NIST: SRM70a; WARD: Apatite }{ }^{\text {b }} \text { Clinochlore }\end{array}$ \\
\hline Basalts & $\begin{array}{l}\text { SARM: PM-S, WS-E; NIST: SRM688; GSJ: JGB1; USGS: BHVO-2, } \\
\text { BIR-1a, DNC-1; AS-IGEM: 1045-94 (MO14), 1017-94 (MO15); } \\
\text { SACCRM: SARM } 5\end{array}$ \\
\hline Andesites & $\begin{array}{l}\text { SARM: DR-N; USGS: AGV-2, BCR-2; GSJ: JA-2, JA-3; AS-IGEM: } \\
\text { 2115-81 (MO1), 2118-81 (MO4), CNACIS: GBW07104 }\end{array}$ \\
\hline Dacites \& Rhyolites & SARM: AC-E, GA, GH, GS-N; USGS: GSP-2, QLO-1; GSJ: JG1a \\
\hline Trachytes & SARM: ISH-G,MDO-G \\
\hline Ultramafic & $\begin{array}{l}\text { SARM: BE-N; USGS: DTS-2B; SACCRM: SARM6, SARM39; } \\
\text { AS-IGEM: VS2113-81 (MU3) }\end{array}$ \\
\hline High alkali & CCRMP: SY4; CNACIS: GBW07109 \\
\hline Anorthosite & SARM: AN-G \\
\hline \multicolumn{2}{|l|}{ Sedimentary materials } \\
\hline Sediments/Sedimentary rocks & $\begin{array}{l}\text { GSJ: JSd-2, JS1-1, JS1-2, JLk-1, JMS-2, JSO-1; USGS: MAG-1; } \\
\text { CNACIS: GBW07315, GBW07316 }\end{array}$ \\
\hline Phosphate & NIST: SRM694 \\
\hline Gypsum & DOM: GYP-D \\
\hline Bauxite & SARM: BX-N \\
\hline Polymetallic nodule & CNACIS: GBW07296 \\
\hline Iron formation & GSC: FeR-3 \\
\hline
\end{tabular}

a Suppliers:

SARM: Service d'Analyse des Roches et des Mineraux, CRPG-CNRS, Nancy, France;

USGS: United States Geological Survey, Denver, Colorado;

NIST: National Institute of Standards and Technology, Gaithersburg, Maryland;

GSJ: Geological Survey of Japan;

SACCRM: South African Bureau of Standards, Pretoria, South Africa;

CCRMP: Canadian Certified Reference Materials Project, CANMET, Ottawa, Canada;

CNACIS: China National Analysis Center for Iron and Steel, Beijing, China;

AS-IGEM: Academy of Sciences: Institute for Geology of Ore Deposits, Petrography, Mineralogy and Geochemistry, Moscow, Russia;

DOM: Domtar Research Center, Senneville, Québec, Canada;

WARD: Ward's Natural Science, USA

b Analyzed by Activation Laboratories Ltd

c Prepared by authors King and Schofield

was developed from our widely used PIXE analysis software package GUPIX (Maxwell et al. 1995) by adding the capability to handle simultaneous XRF analysis. A fundamental parameters treatment of matrix effects for both the PIXE and XRF excitation modes is rigorously incorporated. By "matrix effects" in this context, we mean the influence of the atomic arrangement in the sample in: (i) decreasing the energy of the incoming alpha particles and determining their range; (ii) attenuating the intensity of the incoming X-ray photons; (iii) attenuating the intensity of the outgoing characteristic X-ray photons; and (iv) secondary X-ray fluorescence between elements. (This is the standard definition in ion, electron and photon beam analysis of materials.) 
GUAPX fits the spectra and converts the peak areas to element concentrations using the database, detector properties, and a user-determined instrumental constant " $H$ ", which effectively combines the unknown detector solid angle and the unknown ${ }^{244} \mathrm{Cm}$ source activity. The equation that relates the measured $\mathrm{X}$-ray intensity $Y(Z)$ for element $Z$ to its concentration $C_{Z}$ is:

$$
Y(Z)=H C_{Z} T F_{\mathrm{AP}}(Z)\left\{M_{\mathrm{PIXE}}(Z, \text { geom })+f_{L} M_{\mathrm{XRF}}(Z, \text { geom })\right\} \varepsilon_{Z}
$$

where:

- $T$ is the duration of the measurement;

- $f_{L}$ is the fraction of alpha decays in which a plutonium L X-ray is emitted;

- $F_{\mathrm{AP}}(Z)$ includes various $X$-ray physics parameters for sample element $Z$;

- $\varepsilon_{Z}$ is the relative detection efficiency $(\sim 1.00$ in the energy region $5-10 \mathrm{keV})$; it is calculated from the $\mathrm{Si}$ wafer thickness, Be window thickness and length and pressure of internal nitrogen column; no attempt is made to include the effects of the detector surface layer of incomplete charge collection (ICC);

- $M=$ the matrix effects term for either PIXE or XRF; in each case it is a function of the measurement geometry and of the concentrations of all elements present in the sample.

Equation (1) is rigorously correct provided that the analyte atoms are randomly distributed on the distance scale of X-ray ranges in the sample (microns to tens of microns). The consequences of this assumption are explored in detail in this paper.

Our fundamental parameters plus standards method is a derivative of similar methods widely used in ion beam analysis and in XRF analysis. In these fields, the exciting beam and the (small) X-ray detector are located at well-defined angles with respect to the sample surface. But in the unique APXS geometry there is a wide range of angles for each of these beams. A solution to this problem was developed by Omand et al. (2005), who used Monte Carlo methods to determine a pair of "effective angles" for any APXS. In the FEU APXS calibration geometry at $21.5 \mathrm{~mm}$ sample-detector distance, the values are $19^{\circ}$ (beam) and $24^{\circ}$ (detector). However, on Mars, although the PFM APXS has identical design, the sample-detector distance will be variable and somewhat larger than in the laboratory. Our calculations based on varying the sample distance up to $40 \mathrm{~mm}$ show that this will not have serious consequences. The only element whose concentration results will be affected by more than $1 \%$ in relative terms is $\mathrm{Na}$, where a $4 \%$ effect is seen as the distance is doubled. Since $\mathrm{Na}$ is subject to several significant uncertainties (see below) we do not consider this effect to be a serious issue.

Within GUAPX there are two options to treat any spectrum. The simpler "fixed-matrix" option is the more appropriate approach for treating standards within a calibration exercise. Here, the element concentrations from the GRM supplier's certificate, including those of undetected components such as $\mathrm{H}_{2} \mathrm{O}+, \mathrm{CO}_{2}, \mathrm{Li}_{2} \mathrm{O}$ etc., are used for computation of the matrix effects. A subset of appropriate standards or elements can be chosen to determine the value of the instrument constant $H$. Then the full suite of standards can be fitted by GUAPX to provide concentrations of all detected elements. If the database is accurate, if our knowledge of the detector is complete, and if the methodology of matrix correction is correct, then these concentration values should be equal to the certificate values. We express the results for each element in each GRM as the ratio $R$ between our GUAPX concentration and the certificate concentration; all these $R$-values should be 1.0. Systematic deviations from 1.0 must be explained and appropriate correction factors devised and justified if possible.

The second option - the "iterative-matrix" option-was developed with unknown samples in mind. Here the full set of element concentrations is iterated to consistency, with 
each iteration involving a full, iterative, non-linear least-squares fit of the spectrum. Within each matrix iteration, it is necessary to invoke the closure rule, i.e. to convert all element concentrations to oxide concentrations and then to normalize the latter such that they sum to $100 \mathrm{wt} . \%$. This ensures that the large oxygen concentration plays its role in the matrix computations, despite the fact that it is "invisible", i.e. it contributes no X-rays to the spectrum. Obviously, this option can also be utilized for the calibration procedure, i.e., it can be applied to known standards and to GRMs. Indeed it was the approach taken by Gellert et al. (2006) in their calibration of the MER APXS. While these authors used a different spectrum fitting approach and devised a semi-empirical approach to the matrix corrections, their overall philosophy was the same as in our iterative-matrix approach.

However, there is a limitation with the iterative-matrix approach, in that it cannot account for the effects of several invisible constituents. We refer to oxygen as a "dependent" invisible element, and we assign oxygen to cations to achieve overall charge balance. For multivalent elements that may be abundant, we assume that all $\mathrm{Fe}$ is $\mathrm{FeO}$, all $\mathrm{Mn}$ is $\mathrm{MnO}$, and all $\mathrm{S}$ is $\mathrm{SO}_{3}$. The remaining independent, invisible elements are those with $Z<10$, and can appear in constituents such as $\mathrm{H}_{2} \mathrm{O}, \mathrm{CO}_{2}, \mathrm{~F}, \mathrm{~B}$ and $\mathrm{LiO}_{2}$. We have shown (Campbell et al. 2010) that, when such constituents contribute less than a few wt.\%, our two approaches give almost identical results for the visible element concentrations. But the necessary neglect of independent, invisible elements in the iterative-matrix approach means that the 100 (oxide) wt.\% normalization excludes these constituents, with the inevitable consequence that the matrix effects are then incorrectly computed. Taking as an example the marine sediment standard GBW07316, which contains 21.8 wt.\% of $\mathrm{H}_{2} \mathrm{O}+$ and $\mathrm{CO}_{2}$, the iterative-matrix approach over-estimates the Si concentration by a factor $\sim 1.05$, and the Fe concentration by a factor $\sim 1.28$. We therefore preferred the fixed-matrix approach for the present work.

\section{Fitting the FEU Spectra}

The model spectrum is built using Gaussian peak shapes when the peak height is less than 1000 counts, and the more accurate Voigtian shape when it exceeds 1000 counts. A point-bypoint convolution of the spectrum with a top-hat digital filter function removes the continuous background. Each element contributes several peaks $(\mathrm{K} \alpha 1, \mathrm{~K} \alpha 2, \mathrm{~K} \beta 1, \mathrm{~K} \beta 3$, radiative Auger satellites, etc.): the intensity of the principal X-ray line $(K \alpha 1)$ is a variable of the fit, and the other intensities are held in the known ratios from the database, modified by detector efficiency, X-ray absorbers, and the appropriate combination of PIXE and XRF matrix corrections.

Peaks in X-ray spectra generally display some asymmetry, with tailing events on their low-energy side. The origin of these features is complex, involving both long shelf-like features and steep exponential tails. Their intensity increases rapidly as the X-ray energy decreases. Scholze and Procop (2009) explain all the features in terms of physical processes within the detector. The flat shelves are removed by our digital filter convolution procedure for dealing with background. We determined the parameters of the steep exponential tails by applying a general peak-fitting program to spectra of pure elements and simple compounds, and then incorporated these parameters in GUAPX.

At the low-energy end of the APXS spectrum the $\mathrm{Na}$ and $\mathrm{Mg}$ peaks usually have low intensity and are superimposed on the exponential tails of the more intense $\mathrm{Al}$ and $\mathrm{Si}$ peaks. Some 20 of the GRMs were re-fitted by GUAPX with the tail parameters included. Resulting changes in peak areas of the lightest elements were about $1 \%$ in the $\mathrm{Na}$ case and $3 \%$ for $\mathrm{Mg}$. These changes are small compared to observed variations in $\mathrm{Na}$ and $\mathrm{Mg}$ peak areas arising 
from mineralogy of the GRM and compared to the resulting uncertainties in the $\mathrm{Na}$ and $\mathrm{Mg}$ results. For this reason, additional analyses that included proper tail parameters for the light elements were not included in this calibration exercise. However, we programmed GUAPX to take specific action in two special cases. The first is where a weak Mn peak is invariably superimposed on the Fe tail. The second is $\mathrm{Ca}$, upon whose tail the $\mathrm{K}$ peak sits. The inclusion of a Ca tail only affected $\mathrm{K}$ results at $\mathrm{K}$ concentrations less than $0.2 \mathrm{wt}$.\%. Since Martian K concentrations are typically $<1 \mathrm{wt} . \%$, this step ensured accuracy at these levels.

The fit also has to deal with the scattered Pu L X-rays in the 14-22 keV energy region. The elastically (Rayleigh) scattered X-rays are dealt with in the same manner as the characteristic X-ray peaks of the fluoresced elements. We have given a brief discussion elsewhere (Campbell et al. 2011a) of our Gaussian doublet representation of the inelastically (Compton) scattered peaks.

\section{Procedure for Calibration of the FEU}

In the MSL APXS, three of the six ${ }^{244} \mathrm{Cm}$ sources are specially manufactured open alpha particle sources with a very thin $(\sim 3 \mu \mathrm{m})$ Ti cover foil whose purpose is to prevent any loss by sputtering of radioactive material. The remaining three are conventional sealed XRF sources which emit only Pu L X-rays. Relative to the MER APXS (Gellert et al. 2006), this design increases the relative intensity of that part of the detected spectrum that arises from XRF excitation. The total activity (in Becquerels) of each of the two source subsets is approximately but not precisely the same. Consequently, the value of the parameter $f_{L}$ cannot be assumed equal to the accurately known literature value and has to be determined experimentally. We adopted a simple trial-and-error method of adjusting the values of $H$ and $f_{L}$ until the mean $R$-values for both iron and silicon across the GRM suite were within $1 \%$ of unity. This was straightforward because Si X-rays are excited $100 \%$ by the alpha particles (PIXE) and Fe X-rays $\sim 95 \%$ by the Pu L X-rays (XRF).

Each of our FEU measurements occupied $\sim 24 \mathrm{~h}$, resulting in very favorable counting statistics. Statistical uncertainties in our concentrations and $R$-values for most major and minor elements in the GRMs are therefore small, as will be seen in the results below. In the expected $\sim 3 \mathrm{~h}$ measurements by the PFM on Mars, these uncertainties will be larger. For elements whose peaks have low intensity, however, peak overlaps can greatly increase the uncertainties, and the energy resolution becomes especially important; examples are $\mathrm{P}$ (overlapping the right flank of the intense Si peak), Mn (superimposed on the low-energy tail of the intense Fe peak), and $\mathrm{Na}$ (generally weak peak at extreme low-energy end of spectrum). In the FEU measurements, limitations of the X-ray detector's Peltier cooling unit resulted in an energy resolution of 175-190 eV (FWHM at Mn K line). With the PFM on Mars, these overlaps will be reduced by an expected energy resolution of $\sim 150 \mathrm{eV}$, obtained due to very low ambient temperatures.

The measurements were performed over a period of three years, during which the ${ }^{244} \mathrm{Cm}$ source activity decayed by $\sim 7 \%$, causing $H$ to decrease with time; this effect was corrected for. Small, unavoidable changes in the level of the sample surface within its container added a random fluctuation of several percent in $H$. We therefore normalized the GUAPX total concentration of all detected elements, taken as their usual oxides $\left(\mathrm{SiO}_{2}, \mathrm{CaO}, \ldots\right)$, together with uncombined elements $(\mathrm{Cl}, \mathrm{Br})$, to the certificate value. The final results for our two parameters were $H=0.2246$ and $f_{L}=0.189$, values which were confirmed by results from pure $\mathrm{Fe}$, pure $\mathrm{Si}$, their oxides, and $\mathrm{FeSi}_{2}$. With these values we obtained $R$-values for all detectable elements in sixty GRMs. 
Fig. 2 GUAPX concentration versus certificate concentration for Ti. The vertical intercept provides the concentration offset in the calibration geometry

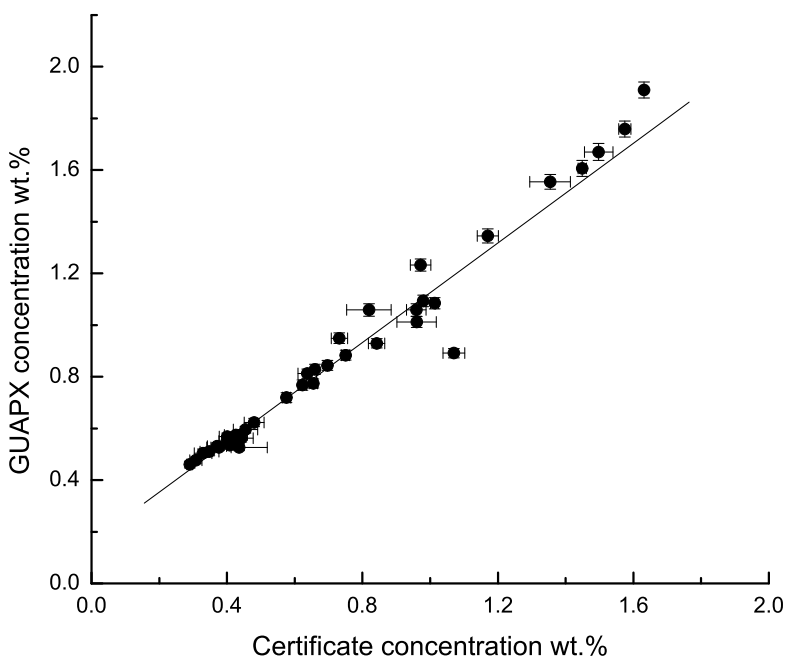

Repeat measurements were conducted after a 2-year interval on a small subset of GRMs measured in the early stages. Concentration values for major elements were unchanged within $\pm 1 \%$ (relative).

Our post-normalization approach was modified for simple chemical compounds where one element has a large concentration and its $R$-value is expected to be low due to detector dead layer effects ( $\mathrm{FeS}$ is an example). Here the normalization factor was determined by comparing fitted and true concentrations of the element (Fe in this example) whose $R$-value is known from the GRM work to be 1.0.

\section{Concentration Offsets in the GRM Spectra}

A number of undesired but unavoidable processes in the APXS can increase the intensity of the X-ray peaks of specific elements, with the consequence that GUAPX will deduce elevated concentrations. The most straightforward cases are: (i) excitation of $\mathrm{Ti} \mathrm{K} \mathrm{X}$-rays in protective cover foils of the three open ${ }^{244} \mathrm{Cm}$ sources, followed by scattering of these $\mathrm{X}$-rays off the sample into the detector; (ii) fluorescence of Zr K X-rays in the detector's entrance collimator by $\mathrm{Pu} \mathrm{L}$ X-rays scattered from the sample; and (iii) fluorescence of $\mathrm{Cr}$ and Ni K X-rays in materials within the sensor head, again due to scattered radiation from the sample. In the $\mathrm{Zr} \mathrm{K} \mathrm{X-ray} \mathrm{case,} \mathrm{this} \mathrm{effect} \mathrm{is} \mathrm{so} \mathrm{large} \mathrm{that} \mathrm{it} \mathrm{swamps} \mathrm{any} \mathrm{Zr} \mathrm{K}$ lines from typical geological samples. We found a small offset of Al K X-rays that are presumably fluoresced from the sample container and the sample stage in the vacuum chamber; such a contribution will not occur for the PFM on Mars and our derived correction will not be applied there.

Another such effect is enhancement of the P K X-ray peak area by Zr L X-rays, the energies of these lines differing by only a few $\mathrm{eV}$.

A third set of peak area enhancements arises because the $\mathrm{K} \mathrm{X}$-ray energies of the elements $\mathrm{K}$ and $\mathrm{Ca}$ are very close to those of $\mathrm{Pu} \mathrm{M} \mathrm{X-rays} \mathrm{scattered} \mathrm{off} \mathrm{the} \mathrm{sample} \mathrm{into} \mathrm{the}$ detector. There is no possibility for these features to be recognized as separate by GUAPX.

These effects may be described in any spectrum analysis code in terms of peak area "offsets" or equivalent concentration offsets. The issues involved are highly technical and so we 
Table 2 Measured values of concentration offsets in the calibration geometry

\begin{tabular}{ll}
\hline Element & Offset \\
\hline $\mathrm{Al}$ & $0.14 \pm .01 \mathrm{wt} . \%$ \\
$\mathrm{P}$ & $0.05 \pm 0.02 \mathrm{wt} \%$ \\
$\mathrm{~K}$ & $-0.01 \pm 0.004 \mathrm{wt} \%$ \\
$\mathrm{Ca}$ & $0.17 \pm 0.01 \mathrm{wt} \%$ \\
$\mathrm{Ti}$ & $0.16 \pm 0.01 \mathrm{wt} \%$ \\
$\mathrm{Cr}$ & $(70 \pm 20) \mathrm{ppm} \mathrm{wt}$ \\
$\mathrm{Cu}$ & $(9 \pm 3) \mathrm{ppm} \mathrm{wt}$ \\
\hline
\end{tabular}

shall report a detailed comparison and assessment of the two approaches elsewhere. As a result of that work we prefer to use concentration offsets, which we determined experimentally by plotting the measured concentration of an element in GRMs versus the expected value. For example, Fig. 2 shows the concentration plot for Ti; the positive offset on the vertical axis indicates that any measured Ti concentration must be corrected downwards by 0.16 wt.\%. In one exception, the concentration offset for P was found by determining the mean "apparent" $\mathrm{P}$ concentration in eight GRMs whose actual concentrations were under 0.01 wt. $\%$.

These offsets, listed in Table 2, apply specifically within the laboratory calibration geometry, for which we have determined an instrumental constant $H$ such that the oxide concentrations sum to $100 \mathrm{wt} \%$. On Mars, the iterative-matrix mode will be used to solve Eq. (1) for the $C_{Z}$ values. The distance from sample to APXS will vary, and hence $H$ will vary from one measurement to the next, causing the sum of the oxide concentrations to differ from $100 \mathrm{wt} . \%$. The iterative mode therefore has to employ a "geometric normalization" to $100 \mathrm{wt} . \%$ of the oxide concentrations. The concentration offsets are treated in the same way.

\section{Comparison of Measured and Fitted Concentrations for the GRMs}

\subsection{Introduction}

In this section we meet the first objective stated in the Introduction, viz., to compare measured concentrations of elements in GRMs with the suppliers' values, which we do via the $R$-values defined earlier. Our presentation is assisted by dividing the GRM suite into several sample groupings. The first group comprises GRMs which are almost entirely a single mineral phase; this is a very important group insofar as the matrix homogeneity permits us to expect $R$-values close to 1.0. In fact, this was demonstrated in the MER APXS case by Campbell et al. (2011b). Further groups are defined through use of a total alkali versus silica diagram, but in view of the numbers of GRMs at hand, the full resolving power of the diagram is not used. Our "reduced" categories are basalts, andesites (including basaltic andesites), dacites (including trachy-dacites and rhyolites), and trachytes. Ultra-mafic rocks form another group, as do high-alkali rocks. The sediment/sedimentary rock category contains a range of rock types, for instance $\mathrm{JSd} 2$, a stream sediment that is presumably very immature because it has mineralogy similar to a basalt (Campbell et al. 2011b). Mean $R$ values for all elements within sample groups and across the entire suite of GRMs are summarized in tabular form during and after the discussion. The elements are also divided into several groups, reflecting mainly the relative contributions of PIXE and XRF to the overall excitation. 
Fig. 3 Iron $R$-values versus supplier-defined concentration in the GRMs. Abbreviations correspond to sample groups defined in text: Min-mineral; Bas_basalt; Anorth-anorthite; And-andesite; Dac_-dacite, trachy-dacite and rhyolite; Trac-trachyte; UM-ultramafic rock; HAR — high alkali rock; Sed-sediment and sedimentary rock
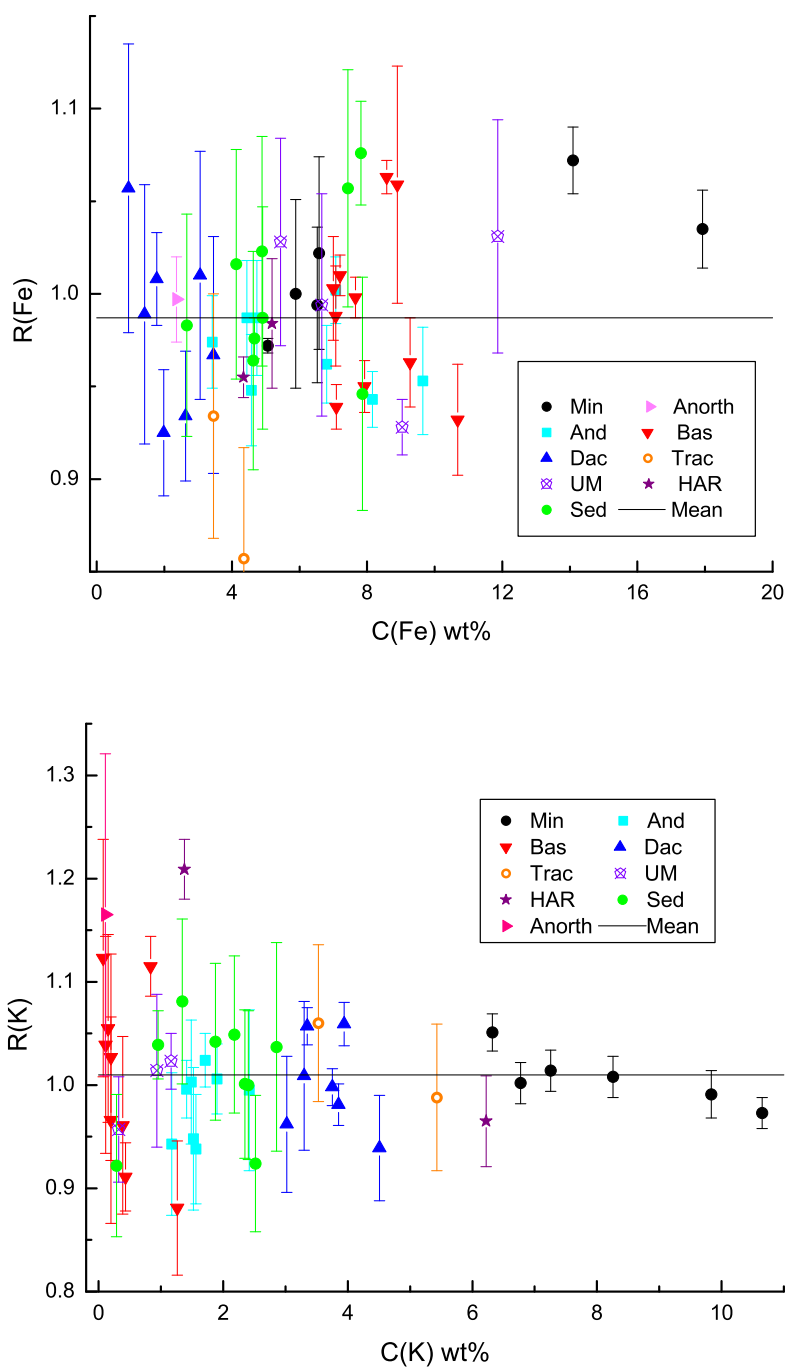

Fig. 4 Potassium $R$-values versus supplier-defined concentration in the GRMs. Abbreviations as in Fig. 3

\subsection{Major Elements Fe, Mn, Zn (Excited $>90 \%$ by XRF)}

For each of these three elements, the overall mean $R$-value is within one percent of unity (where a perfect correlation has $R=1$ ). We show the full results for Fe in Fig. 3; the other two elements have similar plots with larger scatter, reflecting their lower concentrations.

\subsection{Major Elements $\mathrm{K}$ and $\mathrm{Ca}$ (Excited $\sim 90 \%$ by PIXE)}

Again there is excellent agreement of the overall mean $R$-values with unity, with similar uncertainty as for $\mathrm{Fe}$. The mean $\mathrm{Ca} R$-value is $0.99 \pm 0.12$; the three GRMs which are almost mono-mineralic have very high $\mathrm{K} / \mathrm{Ca}$ concentration ratios, which results in overly high values for $R(\mathrm{Ca})$. The $\mathrm{K}$ results, shown in Fig. 4 have an overall $R$-value of $1.02 \pm$ 0.12 , with only one obvious anomaly (SY4). However, Martian concentrations are typically 
Fig. 5 Silicon $R$-values versus supplier-defined concentration in the GRMs. Abbreviations as in Fig. 3

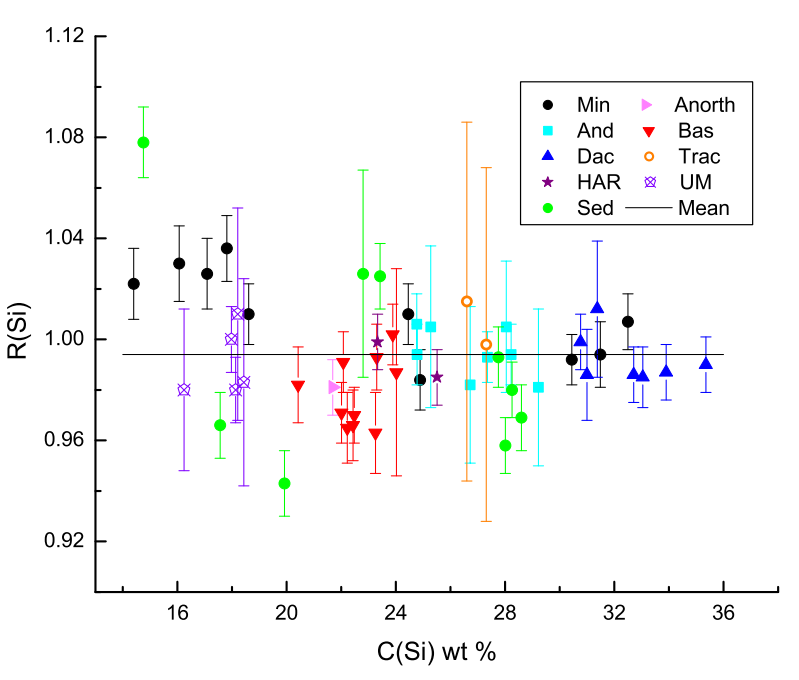

less than $0.5 \mathrm{wt} . \%$. If we consider just the nine data points having concentrations between 0.05 and 0.5 wt. $\%$, their mean $R$-value is $1.02 \pm 0.16$. This is a remarkably good result, considering that for these cases the calcium concentration is $5-10 \mathrm{wt} . \%$, which results in the $\mathrm{K}$ peak being barely visible on the left flank of the Ca peak in the spectra.

\subsection{Titanium (Excited Approximately Equally by PIXE and XRF)}

With a mean $R$-value of 0.99 , Ti follows the trend thus far established.

\subsection{Light Elements $\mathrm{Si}, \mathrm{Al}, \mathrm{Mg}, \mathrm{Na}$ (Excited Exclusively by PIXE)}

Given the excellent results so far, one expects similar outcomes for $\mathrm{Si}$, which is invariably present at high concentration. This is indeed the case, as Fig. 5 shows.

$\mathrm{Al}$ is a much more complex case, as Fig. 6 suggests. It is difficult to make sense of the Al data until one plots the $R(\mathrm{Al})$ values versus the Fe concentration (Fig. 7), the latter being a proxy for increasing mafic mineral content of the GRMs. When the Fe content is low $(<4 \%)$, the GRM suite is dominated by minerals, dacites and rhyolites, and the mean $\mathrm{Al}$ $R$-value is 1.03 . Then $R$ rises steadily as the Fe concentration increases and we proceed through andesites to basalts and some of the ultramafic rocks. Finally, at high Fe content (>10 wt. \%) in two minerals plus bauxite and hornblendite (dominated by hornblende), the $R$-value relapses to a mean of 1.011. It appears that there exists a "best" $R$-value of $1.025 \pm$ 0.06 , and that a systematic departure from it occurs for $\mathrm{Al}$ in increasingly mafic rocks. Al is the first element for which we observe a dependence of the $R$-value upon sample group; reasons are discussed in detail in Sect. 7.

$\mathrm{Mg}$ is a second complex case, as Fig. 8 shows. For the five ultra-mafic rocks, which are dominated by olivine and contain $8-30 \mathrm{wt}$. $\% \mathrm{Mg}$, the $R$-value averages 0.97 . In the minerals group, three cases have high $\mathrm{Mg}$ content, averaging $17.6 \mathrm{wt} . \%$, and their mean $R$ is 1.003 . We must conclude that when $\mathrm{Mg}$ is a major element, its "best" $R$-value is $0.98 \pm 0.08$. However, the overall un-weighted mean $R$-value across the igneous groups is well below 1.0; for trachytes it is extremely low at 0.64 . Basalts as a group tend to lie low in $R$-value, as was the case with the MER APXS calibration data. 
Fig. 6 Aluminum $R$-values versus supplier-defined concentration in the GRMs. Abbreviations as in Fig. 5, plus bauxite

Fig. 7 Aluminum $R$-values versus iron concentration. Abbreviations as in Fig. 3
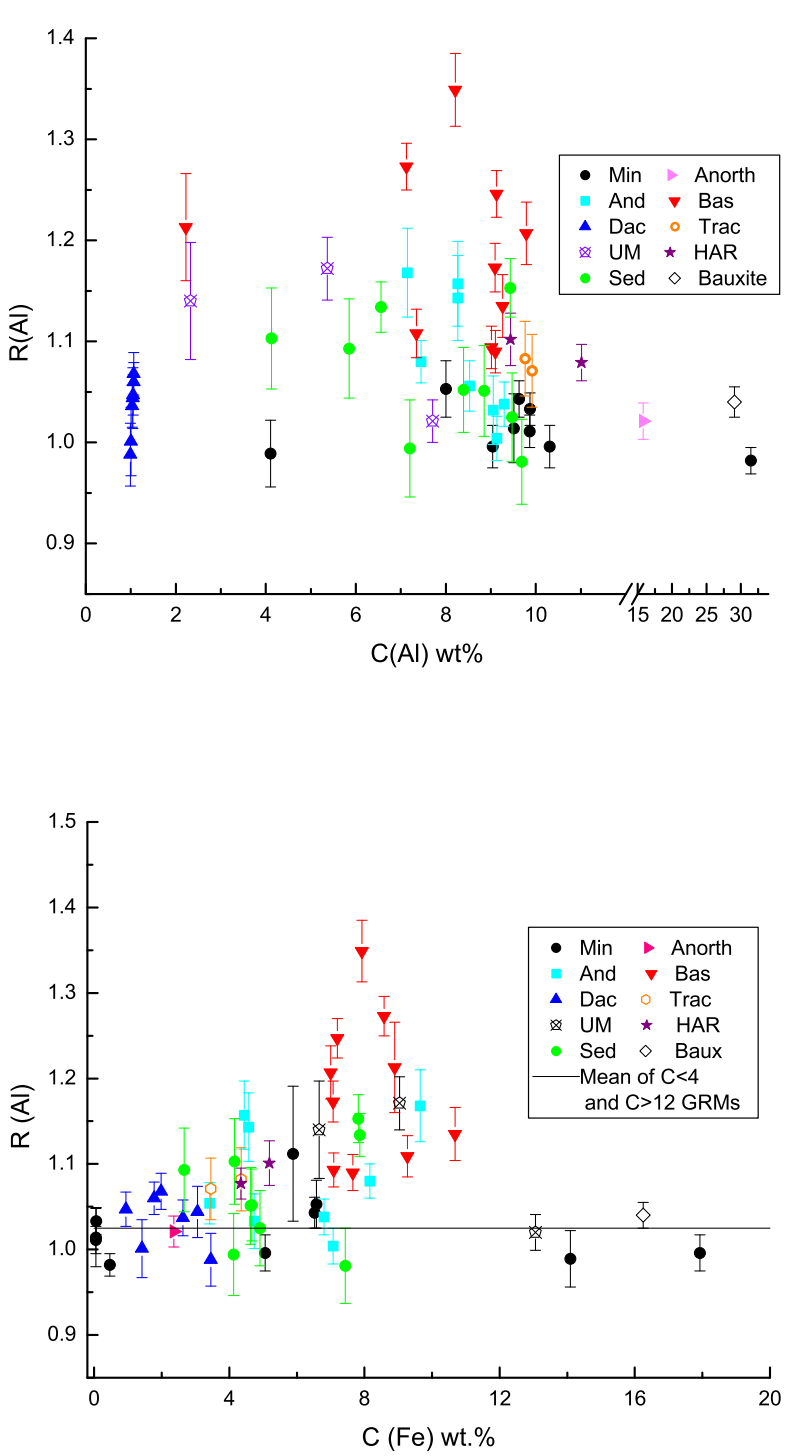

As shown in Fig. 9, $\mathrm{Na}$ in basalts and andesites displays an anomaly similar to that observed for $\mathrm{Al}$ in Fig. 6. The sediments possibly reveal another difference due to mineral content with a low mean $R$-value of $0.78 \pm 0.23$. If basalts, andesites and sediments are excluded from the overall mean $R$-value, we find a "best" value of $0.945 \pm 0.06$, which is sufficiently close to unity to assure us of reasonable consistency with other light elements.

Since it is the four lightest elements which display the most significant sample groupdependent $R$-values, their full results are presented in Table 3 . We should mention that the large scatter within each sample group for these elements might be partly attributed to sample surface roughness, the depth probed by PIXE being only a few microns. 
Fig. 8 Magnesium $R$-values versus supplier-defined concentration in the GRMs. Abbreviations as in Fig. 3

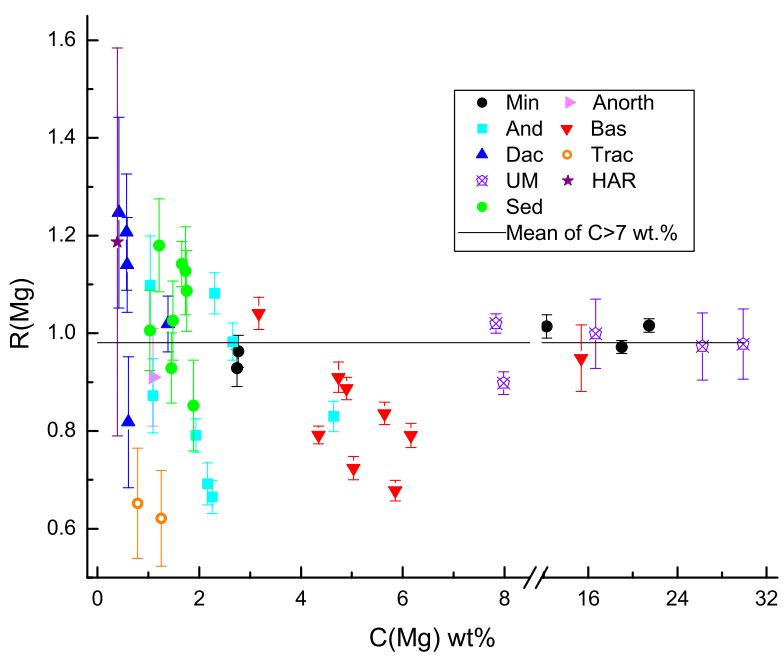

Fig. 9 Sodium $R$-values versus iron concentration. Abbreviations as in Fig. 3

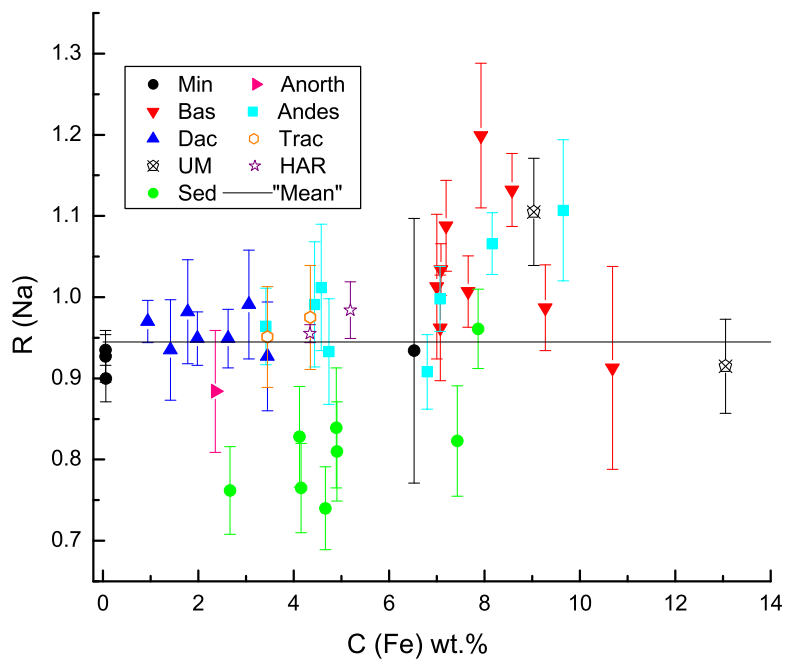

\subsection{Trace Elements with $Z>22$}

There is negligible PIXE contribution in this group. Several of the elements are detected only in a small number of the GRMs. Given the results for Mn, Fe and Zn, we would expect to find that the transition elements have mean $R$-values commensurate with unity. This is indeed the case within large uncertainty estimates which reflect both small peak areas and peak overlaps. We need remark only on a few special cases.

For Cr, many of the standards contain $<0.05$ wt. $\%$, but if we take only the six "highconcentration" cases above 0.15 wt. $\%$, we find a best value of $1.03 \pm 0.16$. So we have good accuracy at those higher concentrations, and this appears to persist down to concentrations of about $0.3 \mathrm{wt} \%$. At the very lowest concentrations the overlap of the $\mathrm{Fe} \mathrm{K} \beta$ escape peak with the $\mathrm{Cr}$ peak may worsen the accuracy. Copper is a similar case, where five data points at concentrations $>0.03$ wt.\% establish $R(\mathrm{Cu})$ as $0.98 \pm 0.08$. 
Table 3 Mean $R$-values by sample group for the lightest elements. Anomalous cases are in bold type

a "Best value" as defined in text

Fig. 10 Strontium $R$-values versus supplier-defined concentration in the GRMs. Abbreviations as in Fig. 3

\begin{tabular}{lllll}
\hline & Si & Al & Mg & $\mathrm{Na}$ \\
\hline Mineral & $1.01 \pm 0.04$ & $1.02 \pm 0.08$ & $0.98 \pm 0.08$ & $0.92 \pm 0.06$ \\
Basalts & $0.980 \pm 0.03$ & $\mathbf{1 . 1 9} \pm \mathbf{0 . 1 6}$ & $\mathbf{0 . 8 4} \pm \mathbf{0 . 2 2}$ & $\mathbf{1 . 0 4} \pm \mathbf{0 . 1 8}$ \\
Andesites & $1.00 \pm 0.02$ & $\mathbf{1 . 0 9} \pm \mathbf{0 . 1 3}$ & $\mathbf{0 . 8 8} \pm \mathbf{0 . 3 2}$ & $\mathbf{1 . 0 0} \pm \mathbf{0 . 1 3}$ \\
Rhyolites & $0.99 \pm 0.02$ & $1.03 \pm 0.06$ & $1.09 \pm 0.34$ & $0.96 \pm 0.05$ \\
Trachytes & $1.01 \pm 0.02$ & $\mathbf{1 . 0 8} \pm \mathbf{0 . 0 6}$ & $\mathbf{0 . 6 4} \pm \mathbf{0 . 0 4}$ & $0.96 \pm 0.04$ \\
U-mafic & $0.99 \pm 0.03$ & $\mathbf{1 . 1 1} \pm \mathbf{0 . 1 6}$ & $0.97 \pm 0.09$ & $1.00 \pm 0.27$ \\
HAR & $0.99 \pm 0.02$ & $\mathbf{1 . 0 9} \pm \mathbf{0 . 0 3}$ & & $0.97 \pm 0.07$ \\
Sediments & $0.99 \pm 0.08$ & $1.06 \pm 0.12$ & $1.04 \pm 0.22$ & $\mathbf{0 . 8 2} \pm \mathbf{0 . 1 4}$ \\
Overall & $0.99 \pm 0.05$ & $1.08 \pm 0.16$ & $0.94 \pm 0.32$ & $0.95 \pm 0.10$ \\
& & $1.025 \pm 0.06^{\mathrm{a}}$ & $0.99 \pm 0.05^{\mathrm{a}}$ & $0.95 \pm 0.06^{\mathrm{a}}$ \\
\hline
\end{tabular}

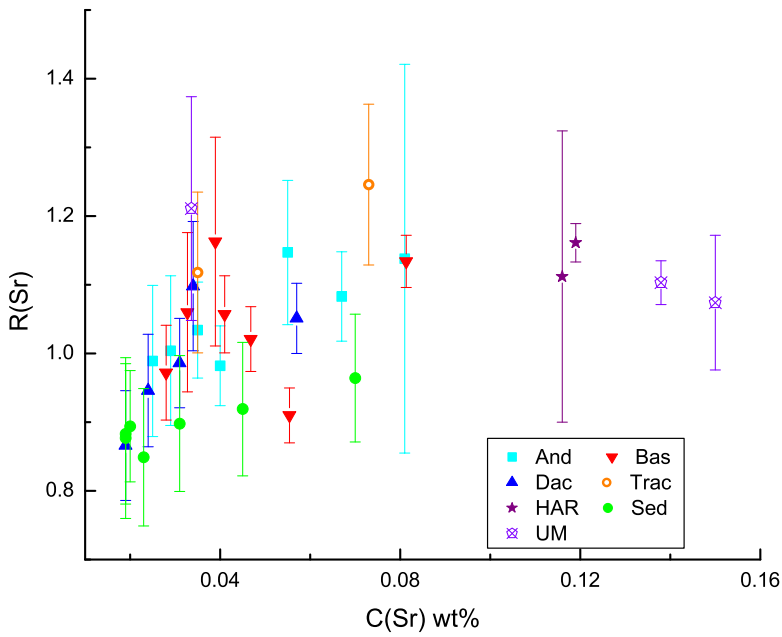

$\mathrm{Br}$ is an important element. In contrast to the MER APXS calibration which had a single Br-containing GRM (MAG-1 with $28 \%$ uncertainty), we now have five GRMs with significant $\mathrm{Br}$ contents and two with low $\mathrm{Br}$ contents. Their mean $R(\mathrm{Br})$ agrees well with the value 0.99 obtained from pure $\mathrm{KBr}$, as shown in Table 4.

A special situation arises for $\mathrm{Rb}$ and $\mathrm{Sr}$, whose $\mathrm{X}$-ray lines overlap with the Compton and Rayleigh scattering features of the $\mathrm{Pu} \mathrm{L} \alpha \mathrm{X}$-rays from the ${ }^{244} \mathrm{Cm}$ source. The results for both elements are similar, and so in Fig. 10 we show only the $\mathrm{Sr}$ data. At $\mathrm{Sr}$ concentrations above $0.07 \mathrm{wt} . \%$, the $R$-value is roughly constant, but it falls steeply as the concentration decreases below that value. At higher concentrations, the Sr X-ray line appears to gain counts from the Rayleigh peak, with the converse situation at low concentrations. A similar interaction occurs between $\mathrm{Rb} \mathrm{X}$-ray line and the Compton peak. The calibration plots can be used to make a post facto empirical correction to an observed $\mathrm{Rb}$ or $\mathrm{Sr}$ concentration.

\subsection{Chlorine, Sulfur and Phosphorus}

These three elements are special cases in two ways. First, in the GRM suite, they appear mainly as trace elements at much lower concentrations than the values encountered on Mars 
Table 4 Summary of results for the GRMs. The third column gives the overall mean $R$-value for each element together with the "best" $R$-value (denoted ${ }^{b}$ ) based on arguments given in Sect. 6; the fourth column provides the corresponding percentage uncertainty for a measured concentration in an unknown sample. The fifth column presents the average of our error estimates for individual $R$-values; each such estimate is compounded from the GUAPX error estimate and the error estimate for the certificate concentration $C$, each taken as $2 \sigma$

\begin{tabular}{|c|c|c|c|c|c|}
\hline$Z$ & $\begin{array}{l}\text { Number of } \\
\text { GRMs used for } \\
\text { mean } R \text {-value }\end{array}$ & $\begin{array}{l}\text { Overall mean } R \text {-value; } \\
\text { b "Best" value; } \\
\pm 2 \sigma\end{array}$ & $\begin{array}{l}\text { Relative error } \\
\text { estimate } \\
(\%)\end{array}$ & $\begin{array}{l}\text { Average of } 2 \sigma \text { error } \\
\text { estimates }(\%) \text { in } \\
\text { individual } R \text { values }\end{array}$ & Remarks \\
\hline $\mathrm{Na}$ & 46 & $\begin{array}{l}0.94 \pm 0.24 \\
0.95 \pm 0.06^{\mathrm{b}}\end{array}$ & $\begin{array}{r}25 \\
6\end{array}$ & 6.6 & $\begin{array}{l}R \text { varies with sample } \\
\text { group—see Table } 3\end{array}$ \\
\hline $\mathrm{Mg}$ & 46 & $\begin{array}{l}0.94 \pm 0.32 \\
0.99 \pm 0.05^{\mathrm{b}}\end{array}$ & $\begin{array}{r}34 \\
5\end{array}$ & 7.1 & $\begin{array}{l}R \text { varies with sample } \\
\text { group-see Table } 3\end{array}$ \\
\hline $\mathrm{Al}$ & 52 & $\begin{array}{l}1.08 \pm 0.16 \\
1.03 \pm 0.06^{\mathrm{b}}\end{array}$ & $\begin{array}{r}15 \\
6\end{array}$ & 2.9 & $\begin{array}{l}R \text { varies with sample } \\
\text { group_-see Table } 3\end{array}$ \\
\hline $\mathrm{Si}$ & 55 & $0.99 \pm 0.05$ & 5 & 1.9 & \\
\hline $\mathrm{P}$ & $\begin{array}{r}10 \\
2\end{array}$ & $\begin{array}{l}1.16 \pm 0.2 \\
0.91 \pm 0.03\end{array}$ & $\begin{array}{r}17 \\
3\end{array}$ & 12 & $\begin{array}{l}\text { GRMs only } \\
\text { Calcium phosphate }\end{array}$ \\
\hline S & $\begin{array}{r}16 \\
4\end{array}$ & $\begin{array}{l}0.90 \pm 0.36 \\
0.93 \pm 0.03\end{array}$ & $\begin{array}{r}40 \\
3\end{array}$ & 18 & $\begin{array}{l}\text { GRMs only } \\
\text { Sulfates only }\end{array}$ \\
\hline $\mathrm{Cl}$ & $\begin{array}{r}19 \\
7\end{array}$ & $\begin{array}{l}1.1 \pm 0.4 \\
0.99 \pm 0.03 \\
0.93 \pm 0.06\end{array}$ & $\begin{array}{r}36 \\
3 \\
6\end{array}$ & $\begin{array}{l}25 \\
3\end{array}$ & $\begin{array}{l}\text { All GRMs } \\
\mathrm{KCl} \\
\text { Sediments with } C>1 \\
\text { wt.\% and Basalt+CuCl } \\
\text { mixtures }\end{array}$ \\
\hline $\mathrm{K}$ & 50 & $1.01 \pm 0.12$ & 12 & 5.7 & \\
\hline $\mathrm{Ca}$ & 45 & $0.99 \pm 0.12$ & 13 & 4.5 & \\
\hline $\mathrm{Ti}$ & 49 & $0.99 \pm 0.12$ & 12 & 5.3 & \\
\hline V & 3 & $1.22 \pm 0.1$ & 8 & 22 & \\
\hline $\mathrm{Mn}$ & 46 & $0.99 \pm 0.13$ & 13 & 9 & \\
\hline $\mathrm{Fe}$ & 52 & $0.99 \pm 0.09$ & 9 & 4 & \\
\hline $\mathrm{Ni}$ & 19 & $1.1 \pm 0.2$ & 19 & 14 & \\
\hline $\mathrm{Cu}$ & 37 & $\begin{array}{l}1.00 \pm 0.32 \\
0.98 \pm 0.08^{b}\end{array}$ & $\begin{array}{r}32 \\
8\end{array}$ & 12 & \\
\hline $\mathrm{Zn}$ & 42 & $0.99 \pm 0.2$ & 21 & 11 & \\
\hline $\mathrm{Ga}$ & 10 & $0.94 \pm 0.19$ & 20 & 16 & \\
\hline As & 2 & $1.05 \pm 0.12$ & 12 & 6.5 & \\
\hline $\mathrm{Se}$ & 1 & $0.85 \pm 0.22$ & 26 & 13 & \\
\hline $\mathrm{Br}$ & 5 & $1.05 \pm 0.2$ & 20 & 17 & \\
\hline $\mathrm{Rb}$ & 10 & & & 6.5 & $\begin{array}{l}\text { Special case: } R \text { is not } \\
\text { constant }\end{array}$ \\
\hline $\mathrm{Sr}$ & 32 & & & 9.2 & $\begin{array}{l}\text { Special case: } R \text { is not } \\
\text { constant }\end{array}$ \\
\hline $\mathrm{Y}$ & 19 & $1.2 \pm 0.3$ & 25 & 24 & \\
\hline W & 5 & $1.01 \pm 0.16$ & 16 & 14 & \\
\hline
\end{tabular}


Fig. 11 Chlorine $R$-values versus concentration. Abbreviations as in Fig. 3

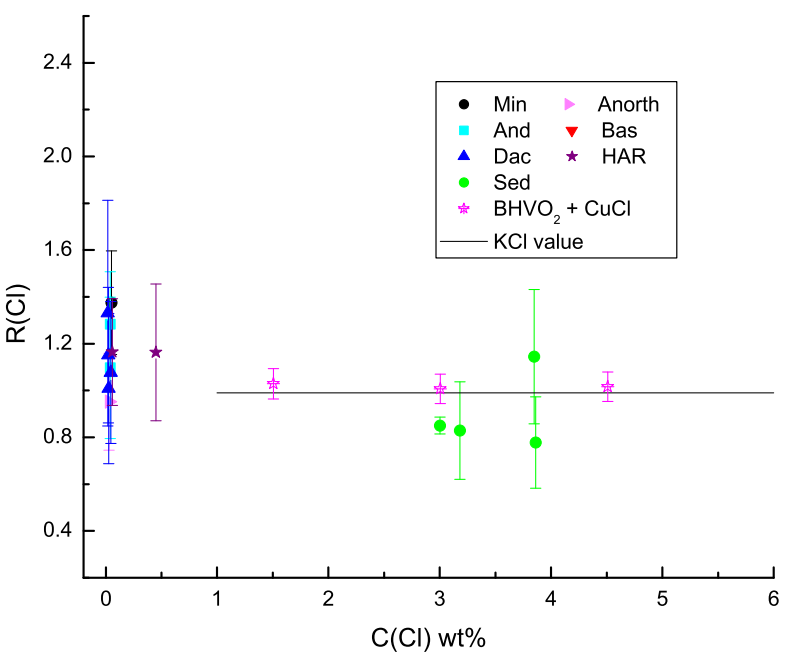

Fig. 12 Sulfur $R$-values versus concentration. Abbreviations as in Fig. 3

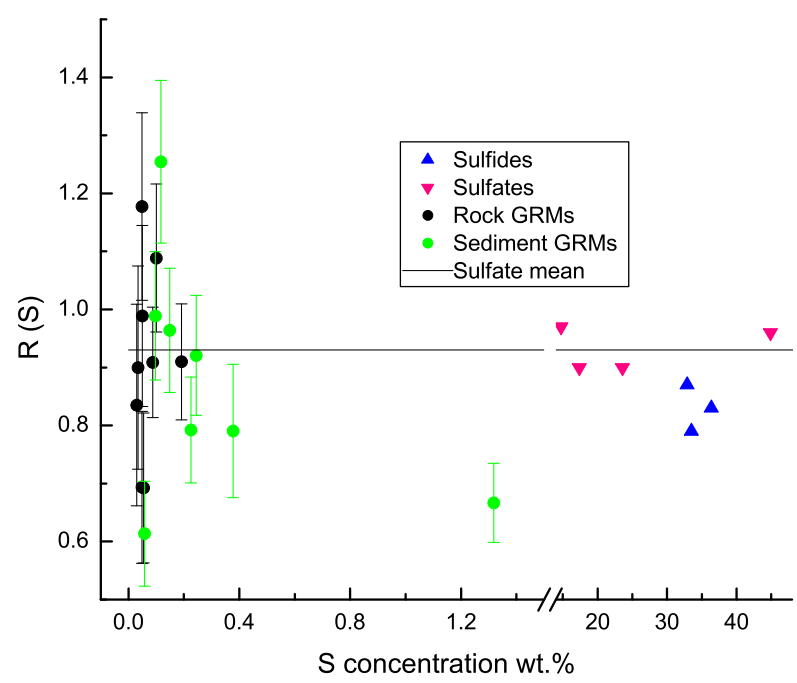

(Brückner et al. 2008). Second, mean $R$-values of 1.0 should not be expected in these cases because of the proximity of their X-ray energies to that of the K absorption edge of Si. This proximity causes loss by attenuation as their X-rays enter the detector through a surface layer of incomplete charge collection, as described by Campbell et al. (2011a). We do not have a sufficiently reliable model of this process to permit its inclusion in the overall detector efficiency model, and so the detection efficiency is significantly over-estimated for P, less so for $\mathrm{S}$, with recovery towards unity almost complete at the $\mathrm{Cl} \mathrm{X}$-ray energy. However, the same behavior holds for the mineral effect with $\mathrm{Si}$ in the sample, if these elements exist predominantly in non-homogeneous grains.

In igneous GRMs, where the $\mathrm{Cl}$ concentration is very low and the element is presumably in trace amounts in one or more phases or hosted in larger amount in a trace phase, the $R$-values significantly exceed 1.0. When we get up to concentrations exceeding $1 \mathrm{wt} . \%$, we have four sediments with an average $R$ of 0.91 . To expand the range of "standards" we manu- 
Fig. 13 Phosphorus $R$-values versus concentration. Abbreviations as in Fig. 3

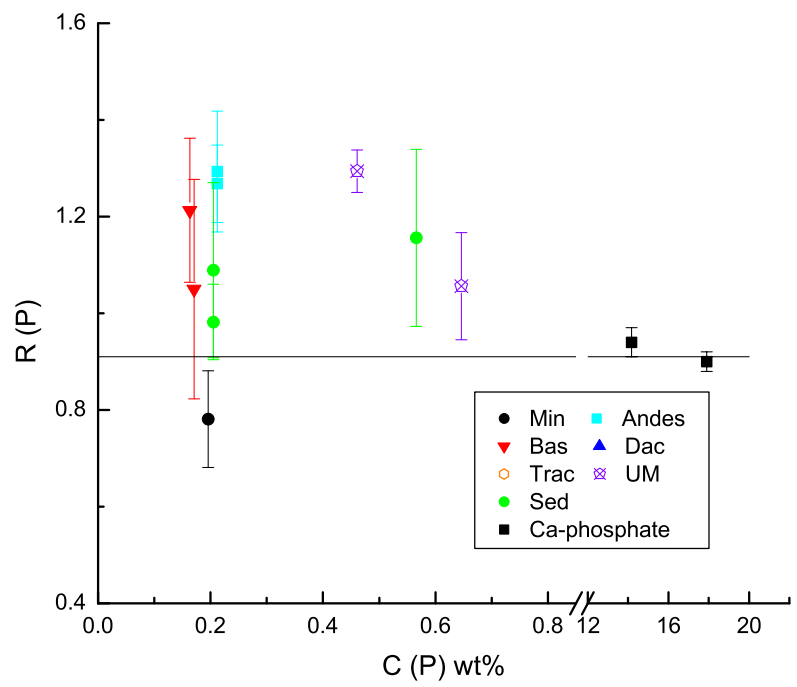

factured mixtures of $\mathrm{BHVO} 2$ basalt and $\mathrm{CuCl}$ in different proportions, pelletizing the mixed powder in a 12-ton press. Such a mixing procedure is justified only in the special case when the theoretical X-ray yield per unit concentration is very similar for the two components of the mixture; here the difference is only $7 \%$. As Fig. 11 shows, the three $\mathrm{BHVO}_{2}+\mathrm{CuCl}$ mixtures $R$-values agree well with the sediment average, their overall weighted mean being $0.93 \pm 0.06$. This in turn agrees with the value of 0.99 obtained with pure $\mathrm{KCl}$.

For $\mathrm{S}$, we have $R$-values (see Fig. 12) from several igneous and sediment GRMs, three sulfides (FeS, $\mathrm{CuS}, \mathrm{ZnS}$ ), and four sulfates $\left(\mathrm{K}_{2} \mathrm{SO}_{4}, \mathrm{CaSO}_{4}, \mathrm{SrSO}_{4}, \mathrm{GYP}-\mathrm{D}\right)$. At low concentrations (i.e. most of the GRMs) there is very large scatter, presumably because we are near the detection limit. For the homogeneous samples, the sulfides fall a little below the sulfates; given the importance of sulfates on the MSL mission, our preferred basic $R$-value is the sulfate mean.

With just two exceptions, the GRMs used for P (see Fig. 13) have concentrations less than $\sim 0.25$ wt. $\%$; these show a mean $R$-value of $1.16 \pm 0.22$, the large scatter reflecting proximity to the detection limit and the $0.05 \mathrm{wt}$.\% concentration offset. The remaining cases (NIST694 calcium phosphate and Ward's apatite) have $R$-values significantly less than unity, as does the mineral GRM Mica-Mg; we have taken the mean $R$-value of these three cases as being the appropriate value for homogeneous matrices. The elevation of the former group of results presumably reflects that in these GRMs the $\mathrm{P}$ is located in an accessory phase such as apatite, whose $\mathrm{X}$-ray yield is much higher than that of $\mathrm{P}$ uniformly distributed within all phases of the sample.

The trend of $R$-values observed for $\mathrm{Cl}, \mathrm{S}$ and $\mathrm{P}$ in homogeneous matrices behaves as expected on the basis of the existence of an incomplete charge collection layer in X-ray detectors of the type used here.

\section{Discussion of the GRM Results}

The overall mean $R$-values across all standards (excluding "others") for each element can now be collected in Table 4, which also includes the "best" values justified above for certain 
cases. The attached error bars represent two standard deviations (95\% confidence level). For most elements we observe agreement with the "target" $R$-value 1.0, albeit within large uncertainty estimates in the case of some trace elements and a few very light elements. This is an important result insofar as it builds confidence in the fitting procedures, the database and the matrix computation approach.

Our uncertainty estimates are also presented in column 4 as percentages to facilitate a direct comparison with the typical error estimates produced by GUAPX for a single sample (column 5). The latter represent only statistical and fitting uncertainties, combined with the uncertainties in the certified concentrations that are provided by the GRM suppliers. The larger spreads for the overall means presumably arise from mineral phase heterogeneity in the GRMs. Column 5 offers a first estimate of the percentage uncertainty that should be attached to APXS analyses of unknown samples. Such estimates will be discussed further in Sect. 11.2.

For the lightest elements, there are clear divergences between the "best" $R$-values and the overall means across all rock types. A consideration of these deviations including an attempt to identify their causes and consequences was defined at the outset as the second objective of this paper.

These effects appear to arise from the mineralogy of the samples, and are best illustrated by the $\mathrm{Al}$ example of Fig. 7. In basalts, the $\mathrm{Al}$ is hosted mainly in plagioclase or feldspathoids which contain very little or no Fe; it is also hosted in pyroxene or glass which contain little $\mathrm{Al}$ but significant Fe; further Fe is contributed by olivine, which contains only traces of Al. When an alpha particle, whose range is only a few microns, interacts (presumably at the surface of the sample) in the felsic phases which host most of the Al, X-ray transmission out of these phases is high. But GUAPX, and similarly the computer code of Gellert et al. (2006), are based on the assumption of a homogeneous distribution of all atoms within the sample, which brings a heavily-absorbing iron component into the assumed matrix. Therefore they compute a lower yield of Al X-rays per unit concentration, i.e. a lower value of $\mathrm{M}_{\mathrm{PIXE}}$ in Eq. (1), from the sample than they would in the case of, say, a pure plagioclase sample. In turn, that causes an over-estimate of the $\mathrm{Al}$ concentration.

The converse situation occurs for Mg in basalts. X-ray diffraction analysis (to be published elsewhere) shows that our basalt GRMs have feldspar and pyroxene as the major minerals. The iron-rich pyroxene hosts the magnesium, and so when an alpha particle excites $\mathrm{Mg}$ X-rays within a surface pyroxene grain, the iron will play a significant attenuating role. But GUAPX handles the Mg X-rays as if they were being transmitted through a matrix whose elemental composition is modified by addition of iron-poor feldspar and it therefore over-estimates the $\mathrm{M}_{\mathrm{PIXE}}$ term, leading to an under-estimate of $\mathrm{Mg}$ concentration. A similar but larger effect is seen for trachytes, where plagioclase feldspar (85 wt.\%) dominates over pyroxene.

\section{Cross-calibration of the PFM}

The approach is similar, but not identical, to the MER APXS approach (Gellert et al. 2006). Two issues must be dealt with. The first is that a different set of ${ }^{244} \mathrm{Cm}$ sources is used in the PFM, raising the possibility of a different balance of activities between the open and the sealed sources. Since all six sources in each instrument have nominally equal activities, this effect is expected to be small, but nevertheless it has the potential to alter the $\mathrm{LX} / \alpha$ ratio $f_{L}$ relative to that of the FEU. In addition, the thickness of the titanium cover foils may change slightly, causing a change in the transmitted alpha particle energy. Since the alpha particle 
cross-sections for X-ray production vary linearly with energy over a span of a few hundred $\mathrm{keV}$, any such effect can be absorbed empirically into the $\mathrm{LX} / \alpha$ ratio. The second issue is the possibility that slight differences in thickness of the beryllium window and the nitrogen column may alter the X-ray detection efficiency for light elements.

\subsection{Comparison of the FEU and PFM ${ }^{244} \mathrm{Cm}$ Sources}

The ${ }^{244} \mathrm{Cm}$ source set intended for the PFM was inserted into the FEU in place of the FEU sources, and a small set of spectra was recorded; this set included GRMs together with CuS and $\mathrm{ZnS}$.

In the two sulfides, the sulfur X-rays are generated entirely by PIXE, and the $\mathrm{Cu}, \mathrm{Zn}$ $\mathrm{X}$-rays by XRF. A measured change factor of $1.031 \pm 0.003$ in the $\mathrm{S} /(\mathrm{Zn}$ or $\mathrm{Cu})$ peak area ratios suggested a $3.1 \%$ increase in the PIXE/XRF ratio. Using a subset of eight GRMs, the $\mathrm{Si} / \mathrm{Fe}$ peak area ratio was determined; it increased by a factor of $1.030 \pm 0.014$. Since Fe X-rays are generated $\sim 95 \%$ by XRF and Si $100 \%$ by PIXE, this is excellent agreement with the sulfides.

One interpretation of the $3.1 \%$ result is that the intensity ratio $\alpha / \mathrm{LX}$ between alpha particles and plutonium L X-rays has increased by $3.1 \%$. But the PFM sources had a new titanium cover foil with the same nominal thickness $(3 \mu \mathrm{m})$ as that used earlier for the FEU source assembly. A very small difference in the actual thickness could cause a change in alpha particle energy. Using published reference cross-sections, assembled from a statistical analysis of experimental data (Paul and Bolik 1993), we estimate that an increase of $140 \mathrm{keV}$ could cause our $3.1 \%$ effect. This would require a thickness difference of $0.5 \mu \mathrm{m}$ from the nominal $3 \mu \mathrm{m}$ value. The alpha spectra were recorded using a silicon surface barrier (SB) detector, and an increase in energy of $\sim 100 \mathrm{keV}$ was observed; because of high counting rates, the SB detector had to be highly collimated, which is not the situation when the APXS is used for analysis, and so the energy measurements must be considered approximate.

We conclude that both potential causes of the observed effect are likely to be in play. The simplest way to handle this as regards future PFM spectra was to increase the $\alpha / \mathrm{LX}$ parameter in the GUAPX source description file by $3.1 \%$. In addition, we incorporated empirical corrections to PFM peak areas of the PIXE-induced elements to reflect observed changes in the peak area ratios $\mathrm{Na} / \mathrm{Si}, \mathrm{Mg} / \mathrm{Si}, \ldots, \mathrm{Ca} / \mathrm{Si}$, between the measurements with FEU and PFM sources; these corrections are at the 1-2\% level and reflect the fact that the locally linear relationships between ionization cross-section and alpha energy differ slightly for each element.

\subsection{Comparison of the FEU and PFM X-ray Detectors}

Six of the GRM spectra taken with the FEU were repeated using the PFM, in order to assess if any difference existed in the efficiency of the two X-ray detectors for the low-energy Xrays of the lightest elements. Such a difference could arise from a different thickness of the dura-beryllium entrance window, a different path length for X-rays in the interior nitrogen column, a different pressure of that column, or a combination of these. The situation was rendered more complex by the use of different ${ }^{244} \mathrm{Cm}$ source configurations on the two units, having different $\mathrm{LX} / \alpha$ intensity ratios. This resulted in different contributions from XRF and PIXE in the PFM and FEU spectra, the peak area ratio between Si and Fe differing by $16 \%$ on average. We therefore extracted from the GUAPX fits the ratios of the peak areas of the three lightest elements $(\mathrm{Na}, \mathrm{Mg}, \mathrm{Al})$ relative to that of $\mathrm{Si}$. Then we took the ratio of these quantities between the PFM and the FEU, as defined in the first column of Table 5. 
Table 5 Comparison of light element peak area ratios between the FEU and PFM APXS units

\begin{tabular}{lll}
\hline Peak area ratio & Value & $\begin{array}{l}\text { Value expected } \\
\text { from } 1 \mu \mathrm{m} \mathrm{Be}\end{array}$ \\
\hline$(\mathrm{Al} / \mathrm{Si})_{\mathrm{PFM}} /(\mathrm{Al} / \mathrm{Si})_{\mathrm{FEU}}$, & $0.984 \pm 0.1$ & 0.987 \\
$(\mathrm{Mg} / \mathrm{Si})_{\mathrm{PFM}} /(\mathrm{Mg} / \mathrm{Si})_{\mathrm{FEU}}$ & $0.96 \pm 0.04$ & 0.965 \\
$(\mathrm{Na} / \mathrm{Si})_{\mathrm{PFM}} /(\mathrm{Na} / \mathrm{Si})_{\mathrm{FEU}}$ & $0.92 \pm 0.02$ & 0.925 \\
\hline
\end{tabular}

The monotonic decrease of the result suggests the presence of additional absorbing material in the PFM. If we attribute this effect to an additional Be absorber, then we can vary its thickness to find a value which yields the observed effect. This value is $1 \mu \mathrm{m}$, which provides transmission factors relative to that of silicon shown in the final column of Table 5. Of course, this additional material in the PFM X-ray path may be nitrogen, but this does not matter, since the attenuation coefficients of both elements have very similar functional relationship upon X-ray energy.

\section{Strategy for PFM Measurements on Unknown Samples}

\subsection{Strategies for Measuring Rocks on Mars}

The first difference in our approach with the PFM on Mars will be the change in the use of GUAPX from fixed-matrix mode to iterative-matrix mode, reflecting variable source-sample geometry and the lack of a well-defined $H$-value. The closure rule will be employed to normalize oxide concentrations to $100 \mathrm{wt}$.\%. Elsewhere, Campbell et al. (2010) have shown that the iterative-matrix mode gives the same results as the fixed-matrix mode provided that the total concentration of independent, invisible elements $\left(\mathrm{H}_{2} \mathrm{O}^{+}, \mathrm{CO}_{2}\right.$, etc. $)$ is low. However, error arises if these constituents exceed several wt.\%. We are therefore continuing to refine our use of the Rayleigh-Compton scatter peak ratio (Campbell et al. 2008) in the hope that it will assist in identifying such cases; this work will be published elsewhere.

The second difference in approach will be the use of the element-dependent empirical correction factors (ECFs) determined in the present work, which will be incorporated in the right-hand side of Eq. (1). For elements whose $R$-values differ significantly from unity in a particular rock type, these ECFs will simply be set equal to the $R$-values of Tables 3 and 4. They will correct for: (i) residual instrumental issues (such as the detector's ICC layer) that are not addressed by GUAPX; (ii) database deficiencies; and (iii) mineralogy influences. Because the mean $R$-value is close to 1.0 for most elements, ECFs are justified only for a few elements. But the choice of actual values in these cases merits careful thought.

The issue is perhaps best addressed by selecting $\mathrm{Al}$ as an example. Our mean $R$-value of $1.08 \pm 0.16$ suggests use of an ECF value 1.08 , but also implies the need to attach a troublingly large uncertainty to derived concentrations. The "best" mean $R$-value of 1.025 is close to unity, which is reassuring, and it carries less than half the uncertainty. But if that best value is adopted, concentration results for basalts (for example) will be wrong by $\sim 20 \%$ (Table 3), and the attached uncertainty will be far too small as an error estimate. If this argument drives us back to the overall mean value, we should recognize that this value is in practice dependent upon the particular overall choice of sample groups that comprise the GRM suite, and is therefore not unique. If the basalts and high-Fe ultramafic rocks had been absent from the GRM suite, the overall mean for Al would have been $1.05 \pm 0.1$.

A way out of these difficulties exists if other evidence, e.g. from X-ray diffraction or laser-induced breakdown spectroscopy, indicates that the sample fits within a specific sample 
group. If a sample is suspected strongly, to take one example, of being basaltic, then an ECF value of 1.2 can be selected for $\mathrm{Al}$ in recognition of this evidence. It might even be the case that the elemental composition from a first fit could suggest the mineralogy in a sufficiently convincing fashion to justify selection of appropriate ECF factors and conduct of a second fit. It follows from all this that during the MSL mission, the final processing of APXS spectra (as distinct from a fast first look) should be an iterative process that is influenced by the results from other instruments.

Phosphorus provides a second, and important, example. Our $R$-value of 0.91 from homogeneous calcium phosphate standards is as expected on the basis of detector properties. But for low concentrations in igneous rocks, we find a much higher $R$-value (1.16) with a very large scatter. In the event of a first Martian analysis suggesting that the sample is dominated by a phosphate, the $0.91 R$-value should be used in a second, refined, analysis. But if low concentrations are observed, the higher $R$-value should be used and a much greater percentage uncertainty attached.

Finally, it is worth noting that the phyllosilicate and mica standards (UB-N, GL-O, clinochlore, Mica-Fe, Mica-Mg) studied here were well-behaved, with $R$-values close to 1.0 for all their elements. Given the richness of the landing site in these materials, this is a reassuring outcome.

\subsection{Estimating Errors of Analyses on Mars}

Table 4 has shown that the real uncertainties in measuring unknown concentrations in the GRMs used here are significantly larger than the GUAPX error estimates, which reflect only fitting and statistical issues for any given spectrum. Even for "well-behaved" elements such as $\mathrm{Si}, \mathrm{K}, \mathrm{Ca}, \mathrm{Fe}$, the scatter of the $R$-values is around twice as large as the individual error estimates. In less well-behaved cases such as $\mathrm{Na}$ and $\mathrm{Mg}$, the difference is much greater. This situation must reflect the mineral phase heterogeneity of rock samples, which violates the necessary, basic assumption of the GUAPX matrix computation that the matrix is homogeneous on the micron scale. In fact it is remarkable, given heterogeneity and the low penetration of alpha particles (a few microns), that the overall mean $R$-values are so close to unity in so many cases. The error estimates of Table 4 will be incorporated into the GUAPX results from the PFM on Mars. Just as the ECF value depends upon the rock type, so also does the corresponding uncertainty, which can be taken from Tables 3 and 4 .

There remains the inescapable fact that on Mars, samples will not be ideally flat and clump-free as they are in our terrestrial calibration exercise. Over and above the matrix effects which we have described here, additional uncertainty will arise from the physical condition of the sample surface, especially for the lightest elements. These effects are wellknown in both XRF and PIXE.

\section{Final Remarks}

An improved understanding of the interaction of the APXS instrument with geological samples emerges from this paper. New issues have been identified, which demand attention. The calibration exercise described here for the MSL APXS has demonstrated how the presence of multiple mineral phases in the sample can detract from analytical accuracy, and has explained the causes. This is a very complex issue, for which universal solutions are difficult to envisage, especially in the context of remote analysis on planetary surfaces. Nevertheless, we have suggested some correction factors based on an understanding of the specific mineralogy of the sample. In two extreme cases the highly heterogeneous GRMs FER3 (iron 
formation) and GBW 07296 (polymetallic nodule) gave highly inaccurate results for minor elements, and hence were excluded from determination of $R$-values. These two examples remind us that many Martian samples may be mixtures, e.g. basalt plus sulfate. Accordingly, an extensive set of such mixtures has been prepared, and exploration of additional corrective approaches and entirely different methodologies for data analysis in such cases has begun.

Acknowledgements This work was financially supported by the Canadian Space Agency and the Ontario Centres of Excellence (PLK, RG, JLC). The assistance of E. Nield in data analysis was greatly appreciated. The paper benefited greatly from excellent in-depth reviews by two anonymous referees.

\section{References}

J. Brückner, G. Dreibus, R. Gellert, S. Squyres, H. Wänke, A. Yen, J. Zipfel, Mars exploration rovers: chemical composition by the APXS, in The Martian Surface, ed. by J. Bell (Cambridge University Press, Cambridge, 2008)

J.L. Campbell, R. Gellert, M. Lee, C.L. Mallett, J.A. Maxwell, J.M. O’Meara, J. Geophys. Res. 113, E06S11 (2008)

J.L. Campbell, S.M. Andrushenko, S.M. Taylor, J.A. Maxwell, J. Geophys. Res. 115, E04009 (2010)

J.L. Campbell, J.A. Maxwell, S.M. Andrushenko, S.M. Taylor, B.N. Jones, W. Brown-Bury, Nucl. Instrum. Methods Phys. Res. B 69, 57 (2011a)

J.L. Campbell, B.N. Jones, W. Brown-Bury, J.A. Maxwell, Nucl. Instrum. Methods Phys. Res. B 269, 69 (2011b)

R. Gellert et al., J. Geophys. Res. 111, JE002555 (2006)

R. Gellert et al., Space Science Reviews, this issue (2012)

R.W. LeMaitre et al., Igneous Rocks: A Classification and Glossary of Terms, Recommendations of the International Union of Geological Sciences, Sub-commission of the Systematics of Igneous Rocks (Cambridge University Press, Cambridge, 2002)

J.A. Maxwell, W.J. Teesdale, J.L. Campbell, Nucl. Instrum. Methods Phys. Res. B 95, 407 (1995)

M. Omand, J.A. Maxwell, J.L. Campbell, Nucl. Instrum. Methods Phys. Res., Ser. B 229, 123 (2005)

H. Paul, O. Bolik, At. Data Nucl. Data Tables 54, 75 (1993)

F. Scholze, M. Procop, X-Ray Spectrom. 38, 312 (2009)

S.W. Squyres, R.E. Arvidson, S.W. Ruff, R. Gellert, R.V. Morris, D.W. Ming, L. Crumpler, J.D. Farmer, D.J. des Marais, A. Yen, S.M. McLennan, W. Calvin, J.F. Bell III, B.C. Clark, A. Wang, T.J. McCoy, M.E. Schmidt, P.A. de Souza Jr., Science 320, 1063 (2008) 